\title{
Suction controlled drying and wetting cycle effects on the volumetric behaviour of a lime-treated high plasticity clay
}

\author{
Marco Rosone ${ }^{1, a}$, Camillo Airò Farulla ${ }^{1}$, Alessio Ferrari ${ }^{1}$, Claudio Torta $^{1}$ and Clara Celauro ${ }^{1}$ \\ ${ }^{1}$ Department of Civil, Aerospace, Environmental and Materials Engineering (DICAM) - University of Palermo, Palermo, Italy
}

\begin{abstract}
The paper presents some experimental results collected on samples recovered from an experimental embankment obtained by compacting a lime-treated clay. Samples were collected soon after the in situ compaction and they were cured in controlled environmental conditions for at least 18 months. Mercury intrusion porosimetry tests (MIP) were carried out on freeze-dried specimens to characterize the microstructure of the material. In order to assess the durability of the improved material, laboratory tests focused on the effects of cyclic variations of the degree of saturation on the water retention properties and the volumetric behaviour of the stabilized clay. Collected results show that the lime-treated clay undergoes an almost irreversible volumetric behaviour; this irreversible contraction is associated to severe drying processes, while wetting paths do not produce significant volumetric deformations.
\end{abstract}

\section{Introduction}

Lime stabilization of fine soils is an advanced technology among those that promote sustainable use of natural resources. The technique is aimed at improving the physical, chemical and mechanical properties of the clays that otherwise would not be suitable for these purposes. Then, it allows the re-use of clayey soils in the construction of transport infrastructures, minimizing the need for suitable materials from borrow-pits and the need to transport waste soils to these lands. Furthermore, this technique permits, when well managed, a significant improvement in both workability and the mechanical properties of the treated clay.

As proved by many studies in this field, lime treatment induces a quick modification of the chemical and physical characteristics of the treated clay due to the absorption of $\mathrm{Ca}^{2+}$ ions by the clay particle surfaces by cation exchange.

Afterwards, more complex chemical reactions develop with time in the lime-soil mixture: in such a high $p H$ environment the dissolution of the clay silica and alumina $\left(\mathrm{SiO}_{2}, \mathrm{Al}_{2} \mathrm{O}_{3}\right)$ and their reaction with the lime calcium produces the development of calcium-silicatehydrates $(\mathrm{CSH})$ and calcium-aluminate-hydrates $(\mathrm{CAH})$, thus creating cementitious bonds within the soil [1]. These bonds are responsible for the improvement of the mechanical properties of the treated soil in terms of an increase in shear strength and reduction of the compressibility [2].

Basic reactions in the lime treatment process are quite well understood and so is the consequent mechanical improvement, mainly in terms of bearing capacity, shear strength and compressibility of the treated clays [3-6] Nonetheless, some aspects may be of concern mainly during the construction phase due to variability of the clay characteristics. Serious attention should be paid when defining the in-field execution procedures in order to guarantee the required performances [7].

Furthermore, despite the quite wide use of the lime treatment technique, so far not many studies deal with the long term behaviour of the treated clay or the effect of repeated loading or variation in the boundary hydraulic conditions [8]. In particular, a very interesting aspect to be clarified is the one related to the durability in time of the mechanical properties gained by the treatment, in relation to the repeated variations in the degree of saturation of the material as laid in situ.

The results presented in the paper refer to a wide experimental programme carried out during the construction of a main extra-rural state road in Sicily. A high plasticity clay, available in large quantities after the excavation work, was studied in order to define the technical and economic feasibility of the treatment. A research programme was defined based on a field trial specifically made for defining the correct execution procedures with regard to each single production phase that could affect the final performance of the structure. Indeed, a complete geotechnical characterization, an evaluation of the mechanical properties as well as one of the deformation characteristics of the material as extracted from the field trial, was carried out.

With the aim to characterize the microstructure of lime-treated high plasticity clay, mercury intrusion porosimetry $(M I P)$ tests were carried out on a specimen sampled soon after the in situ compaction and treated in

\footnotetext{
a Corresponding author: marco.rosone@unipa.it
} 
controlled environmental conditions $\left(T=20^{\circ} \mathrm{C}\right.$ and $U_{r} \geq$ $90 \%$ ) for at least 18 months.

Finally, in order to assess the stability in time of the geotechnical characteristics, the paper presents test results of repeated wetting and drying cycles carried out in a suction-controlled oedometric device and by means of the vapour equilibrium technique.

\section{Material properties and experimental programme}

The material was recovered from an experimental embankment built in the Favarella district, in the province of Caltanissetta, Sicily. Some geometric and constructive details of the experimental embankment are reported in [9]. Before the treatment and the compaction stage (corresponding to the Standard Proctor energy level), the clay was partly disaggregated by means of a motor grader, to obtain a material with apparent grain size distribution through $d=31.5 \mathrm{~mm}$ and $d=4.76 \mathrm{~mm}$ sieves, respectively, equal to $p_{31.5}=100 \%$ and $p_{4.76}=$ $63 \%$.

Undisturbed samples used for laboratory experiments were taken soon after the construction of the embankment, by means of metal thin-walled tubes inserted at depths corresponding to $0.30 \div 0.60 \mathrm{~m}$ and $0.90 \div 1.20 \mathrm{~m}$ from the finished surface of the embankment. Spreading controls carried out with measurement of the mass of lime spread on the surface, have shown that the quantity of lime considered as actually used in the layers is equal to $2.3 \%$ (Airò Farulla et al., 2014). The initial consumption of lime, obtained from laboratory tests was slightly less than $2 \%[10,11]$. The tested samples, recovered at the time of the construction of the embankment, were wrapped in multiple layers of plastic film, and treated for a period of 18 months in an air-conditioned cabinet with a temperature $T=20^{\circ} \mathrm{C}$ and relative humidity $U_{r} \geq 90 \%$.

The following properties were determined for the tested samples: grain size distribution consisting of gravel fraction $f_{\text {gravel }}=1 \div 6 \%$, sandy fraction $f_{\text {sand }}=9 \div 17 \%$, silty fraction $f_{\text {silt }}=39 \div 59 \%$, clayey fraction $f_{\text {clay }}=24 \div$ $52 \%$; liquid limit $w_{l}=51 \div 53 \%$, plasticity index $P I=24 \div$ $28 \%$ and activity index $I_{a}=0.54 \div 1.00$; soil specific weight $\gamma_{s}=26.3 \div 26.4 \mathrm{kN} / \mathrm{m}^{3}$; water content $w=17.6 \div$ $21.8 \%$; dry unit weight $\gamma_{d}=15.9 \div 17.4 \mathrm{kN} / \mathrm{m}^{3}$; void ratio $e_{0}=0.52 \div 0.65$.

MIP tests were performed using a porosimeter (Pascal 140-240 series, Thermo Scientific Corp.) attaining a maximum intrusion pressure of $200 \mathrm{MPa}$, which corresponds to an entrance pore diameter of approximately $7 \mathrm{~nm}$. Macropores were detected at the beginning of the tests in the low pressure unit operating between 0 and $400 \mathrm{kPa}$. The advancing non-wetting contact angle between mercury and the clay minerals was assumed to be $140^{\circ}$ [12].

MIP tests were carried out on an untreated sample, compacted at optimum standard Proctor condition $\left(\gamma_{d}\right.$ $=16.1 \mathrm{kN} / \mathrm{m}^{3}$ and $w=20.3 \%$ ), and on a lime treated clay sample coming from the embankment.
Samples for the MIP tests were dehydrated by means of a freeze-drying technique consisting in quick freezing the samples by dipping them in liquid nitrogen (boiling temperature $-198^{\circ} \mathrm{C}$ ) and sublimation with vacuum pump at $-60^{\circ} \mathrm{C}$ for $24 \mathrm{~h}$.

In order to assess the water retention properties of the treated material in a wide range of suction, both in drying and in wetting paths, various techniques for suction control were used. The axis translation technique (air overpressure method) applied in an oedometric apparatus was used to control matric suction in the range of $0.01 \div$ $0.80 \mathrm{MPa}$, whereas the vapour equilibrium technique was used to impose total suction in the range of $2 \div 110 \mathrm{MPa}$. When using the vapour equilibrium technique, the stationary condition was considered to have been achieved when the difference in weight of the specimen between two successive measurements, carried out at a distance of one week, was lower than $0.1 \%$.

A fluid displacement technique was used to measure the volume of each tested specimen after equalization at the imposed suction with the vapour equilibrium technique.

\section{Results analysis}

The most relevant results of the MIP are reported in terms of the cumulative volume of intruded mercury and the value $\Delta\left(V_{i} / V_{\text {tot }}\right) / \Delta \log d$, which expresses the frequency of the pores, as a function of equivalent diameter $d$. Figure 1 shows how the untreated compacted clay presents a typical double porosity pore size distribution, characterized by a very well marked peak in the field of micropores ( $d=0.5 \mu \mathrm{m})$ and a uniform distribution in the macropore field, that is the range of diameter between 3 and $100 \mu \mathrm{m}$. In particular, assuming as a boundary limit the diameter $d=1 \mu \mathrm{m}$, from the cumulated volume curve (Fig. 1a) it can be calculated that macropores characterize a little less than $20 \%$ of the total intruded porosity. These results are typical for natural clay compacted in optimum conditions [13].

The intruded volume in the treated sample increases due to the lower state of compaction $\left(\gamma_{d}=16.5 \mathrm{kN} / \mathrm{m}^{3}\right)$. The treated clay has a bimodal pore size distribution, with a peak slightly more marked for $d \geq 10 \mu \mathrm{m}$, as could be expected for an aggregated structure. The modal value of the diameter in the field of the macropores is equal to about $60 \mu \mathrm{m}$, while the total volume of macropores is more greatly increased (about $75 \mathrm{~mm}^{3} / \mathrm{g}$ ) than the untreated clay ( about $30 \mathrm{~mm}^{3} / \mathrm{g}$ ) .

Minor variations in terms of intruded volume are found in the field of micropores even though the pore distribution is somewhat different. In the field of micropores, untreated clay shows the modal value 0.41 $\mu \mathrm{m}$ while the treated clay has a much lower modal value $(d=0.06 \mu \mathrm{m})$. Furthermore, treatment with lime reduces the micropores intruded volume (from 159 to 147 $\left.\mathrm{mm}^{3} / \mathrm{g}\right)$. 
a)

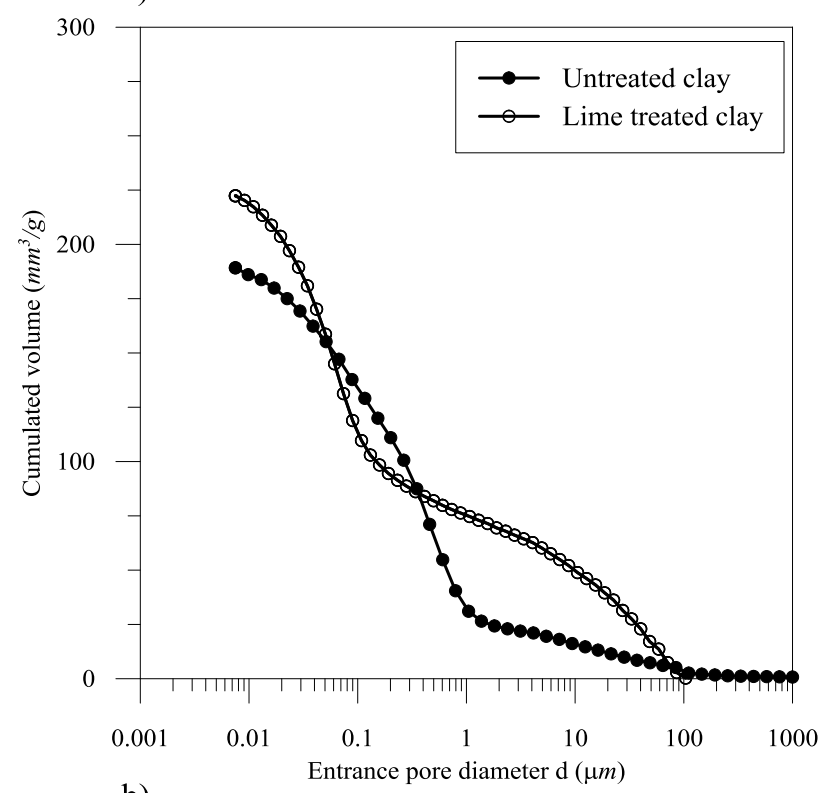

b)

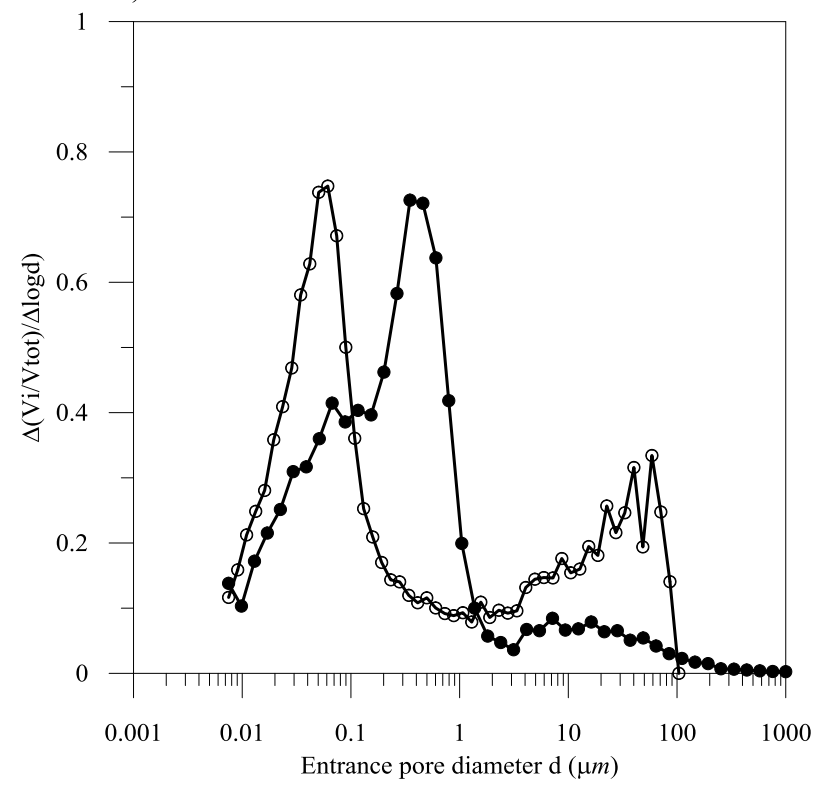

Figure 1. Cumulated intruded volume (a) and pore size frequency (b) as a function of equivalent pore diameter for untreated clay and lime treated clay.

The results of the mechanical tests carried out during the early stage of the research, highlight the already wellknown beneficial effects of the treatment on the strength and deformability of the clay. For instance in Figs. 2 and 3 the oedometric tests results are reported with the purpose of highlighting the effect of saturation and the successive loading/unloading paths on the volumetric behaviour of treated and untreated clay compacted with laboratory procedure. During the initial phase of saturation, obtained by subjecting the specimen immersed in water to a total vertical pressure $\sigma_{v}=10 \mathrm{kPa}$, the untreated material underwent a remarkable swelling, corresponding to axial strain, $\varepsilon_{a}$, equal to $-5.82 \%$ and a void ratio variation $\Delta e=0.07$, while the embankment material essentially kept its volume intact $\left(\varepsilon_{a}=-0.45 \%\right.$, $\Delta e=0.01)$ (Fig. 2).

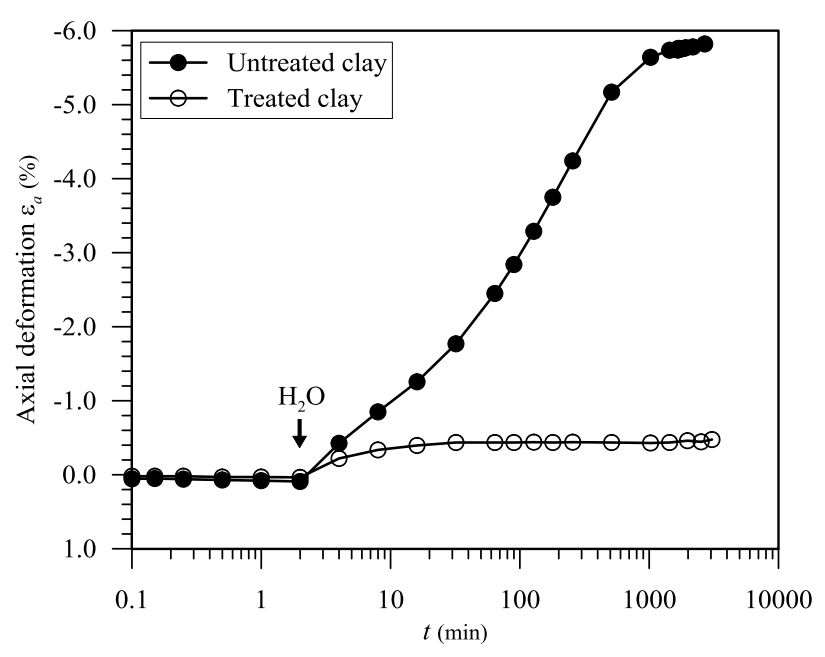

Figure 2. Swelling during saturation stage under oedometric condition $\left(\sigma_{v}=10 \mathrm{kPa}\right)$.

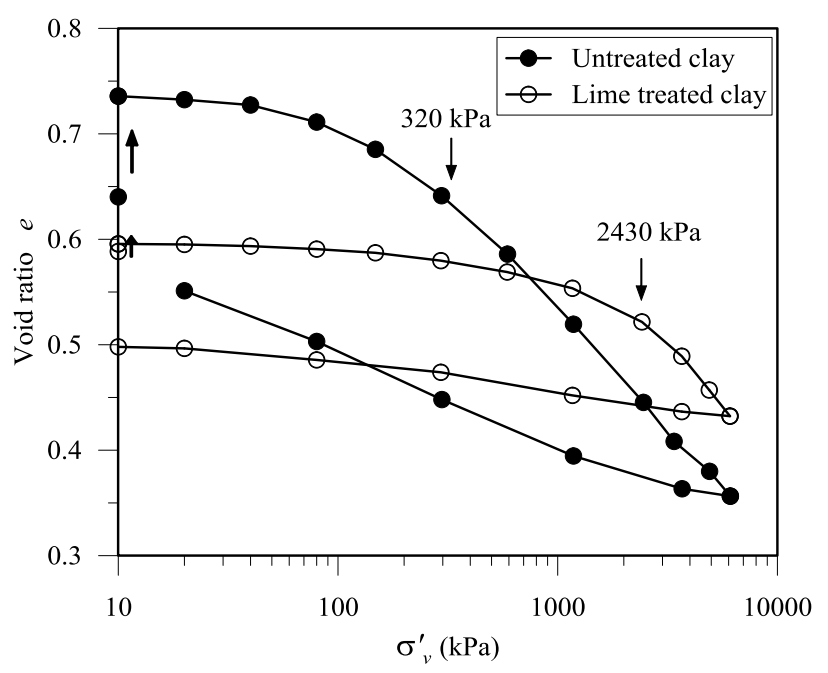

Figure 3. Oedometric curves for compacted untreated and in situ treated clay.

The results of the subsequent stages of loading and unloading expressed in terms of $e-\log \sigma_{v}^{\prime}$ are reported in Fig. 3. The yield stress, determined by the Casagrande method, undergoes a strong increase, from $\sigma_{v, \max }^{\prime}=320$ $\mathrm{kPa}$ for the untreated material, to $\sigma_{v, \max }^{\prime}=2430 \mathrm{kPa}$ for the embankment material. However, it is observed that, passing the yield strength, the slope of the straight portions of the two oedometric curves is practically the same $\left(c_{c}=0.249 \div 0.258\right)$, even if the swelling coefficient $c_{s}$ of the compacted untreated clay $\left(c_{s}=0.078\right)$ is about three times that of treated clay $\left(c_{s}=0.024\right)$.

Although the improvement of the properties of the treated clay is a well-known result, the stability of such properties in time, especially with seasonal variation in weather, at the moment appears to be unclear and, at the same time, a key topic to evaluate the durability of the work.

Fig. 4 shows the results, expressed in terms of void ratio and degree of saturation $S_{r}$, as a function of applied matric suction $s$, of the cycling matric suction tests performed at constant net vertical pressure $\left(\sigma_{v, n e t}=50\right.$ 
$\mathrm{kPa})$. The range of variation of suction during the test, $s=$ $0.01 \div 0.8 \mathrm{MPa}$, was selected because minimum variation of water content $(\Delta w=-0.08 \%)$ at constant void ratio was measured during first equalization at $0.8 \mathrm{MPa}$. During the first cycle, the variation of suction was performed by steps while in subsequent cycles, the maximum variation of suction was applied instantaneously.

The evolution of the void ratio as applied matric suction varied (Fig. 4a) shows that during the wetting and drying cycles the sample undergoes a very low void ratio variation $(\Delta e=0.002)$, reversible in nature. During the first wetting, as well as during the subsequent, the specimen reaches almost complete saturation while in the following drying it starts significantly to desaturate for suction higher than $0.05 \mathrm{MPa}$.

Variations in the degree of saturation take a different course varying the considered cycle. During the first cycle, the degree of saturation differences, at constant matric suction, are linked to the effect of the hydraulic hysteresis [14]. In subsequent cycles, the cyclical variations of degree of saturation is reduced a lot, although it should be noted a slight tendency to reduce the degree of saturation in the third and fourth round of drying $\left(\Delta S_{r}=-0.003\right)$. Then, it can be concluded that the degree of saturation $S_{r}$, as it is shown in Fig. 4b, cyclically varies in the range between 0.92 and 1.00 without significant variation in successive cycles of suction.

On the basis of the collected results, it is possible to claim that the processes inducing a reduction of suction do not intervene significantly on the hydro-mechanical behaviour of such material. Different behaviour can be observed in the case of wide cyclic variation covering a suction range greater than the_level of suction operating on the specimen as a result of the compaction process and following treatment.

In order to highlight this peculiar behaviour, the results of several cycles of wetting and drying applied by varying total suction between 2 and $110 \mathrm{MPa}$ (Fig. 5) and 32 and $110 \mathrm{MPa}$ (Fig. 6) are reported. The evolution of the volumetric strain $\varepsilon_{v}$ (Figs. 5a and 6a) due to cyclic suction variations is characterized by the accumulation of significant deformations of shrinkage. Always in the same diagrams, it can be observed that these deformations occur, mainly, in the first cycle of wetting and drying. Such behaviour tends to become reversible in nature, although a tendency to cumulate shrinkage deformations during the last cycle of the sample subjected to 32 and $110 \mathrm{MPa}$ is recognized.

The evolution of the water content $w$ of the specimens (Figs. 5b and 6b) is characterized by different behaviour. During the first equalization stage at $2 \mathrm{MPa}$ in the series of cycles between 2 and $110 \mathrm{MPa}$, the specimen slightly decreases the water content $(\Delta w=-$ $0.01 \%$ ) at constant volume and only after the first equalization stage at total suction equal to $110 \mathrm{MPa}$ does it significantly reduce the water content $(\Delta w=-15.7 \%)$. The specimen subjected to cycles between 32 and 110 $\mathrm{MPa}$ continuously reduces the water content after the first equalization to $32 \mathrm{MPa}(\Delta w=-13.3 \%)$. These results highlight that the initial total suction can be assumed to be equal to $2 \mathrm{MPa}$.

However, the resulting reduction of water content is generally very significant during the equalization stage of the first cycle while it is more modest, but still significant in the second and the third cycles.

The irreversible variations of water content occurring almost exclusively in the first cycle of suction, are primarily due to the hydraulic hysteresis phenomenon.

a)

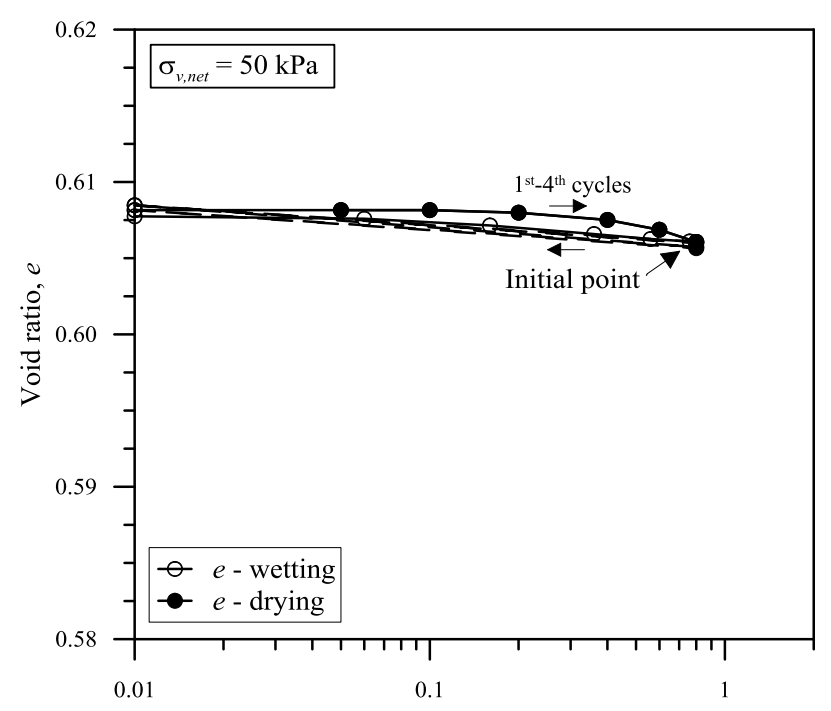

b)

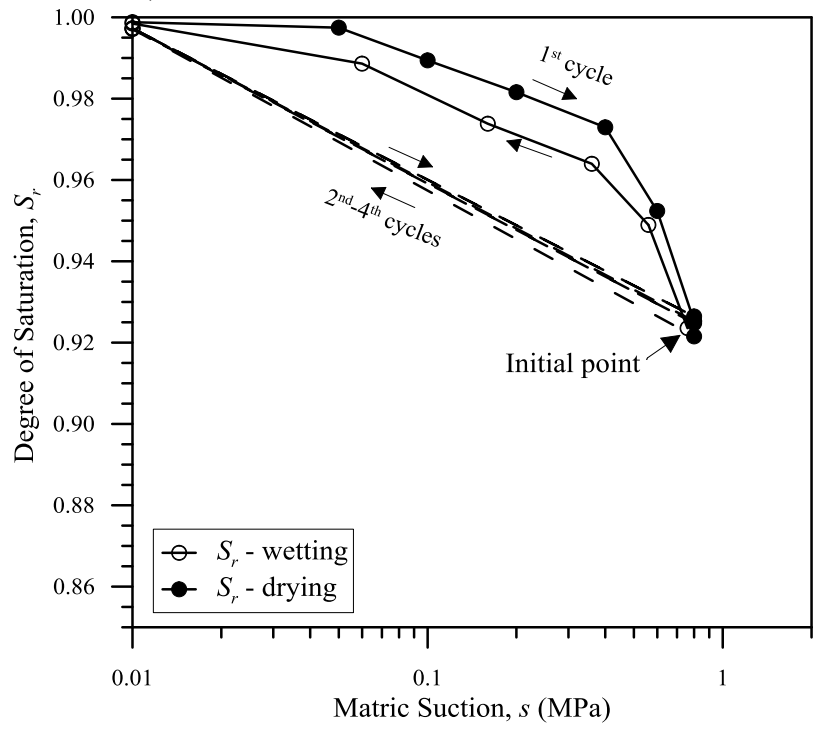

Figure 4. Void ratio, $e$, (a) and degree of saturation, $S_{r}$, (b) during suction cycle between 0.01 and $0.80 \mathrm{MPa}$.

Volumetric deformation variation measured in the phases of wetting and drying the individual cycles are represented in Figs. 5c and 6c. In the first equalization step at the suction of $32 \mathrm{MPa}$ (Fig. 6c) the sample undergoes a pronounced deformation of volumetric shrinkage of the order of $4 \%$. As already reported, the specimen subjected to the suction of $2 \mathrm{MPa}$ (Fig. 5c) does not undergo a significant volumetric shrinkage $\left(\Delta \varepsilon_{\mathrm{v}}=\right.$ $0.02 \%$ ). 

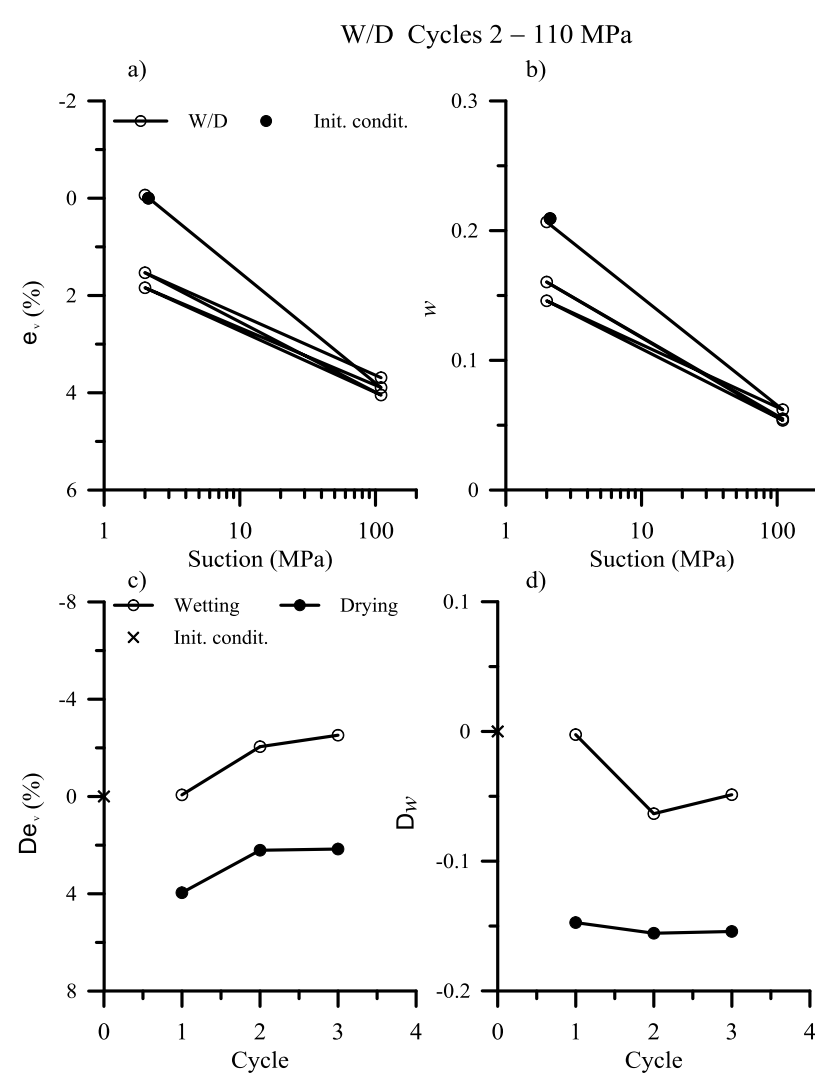

d)
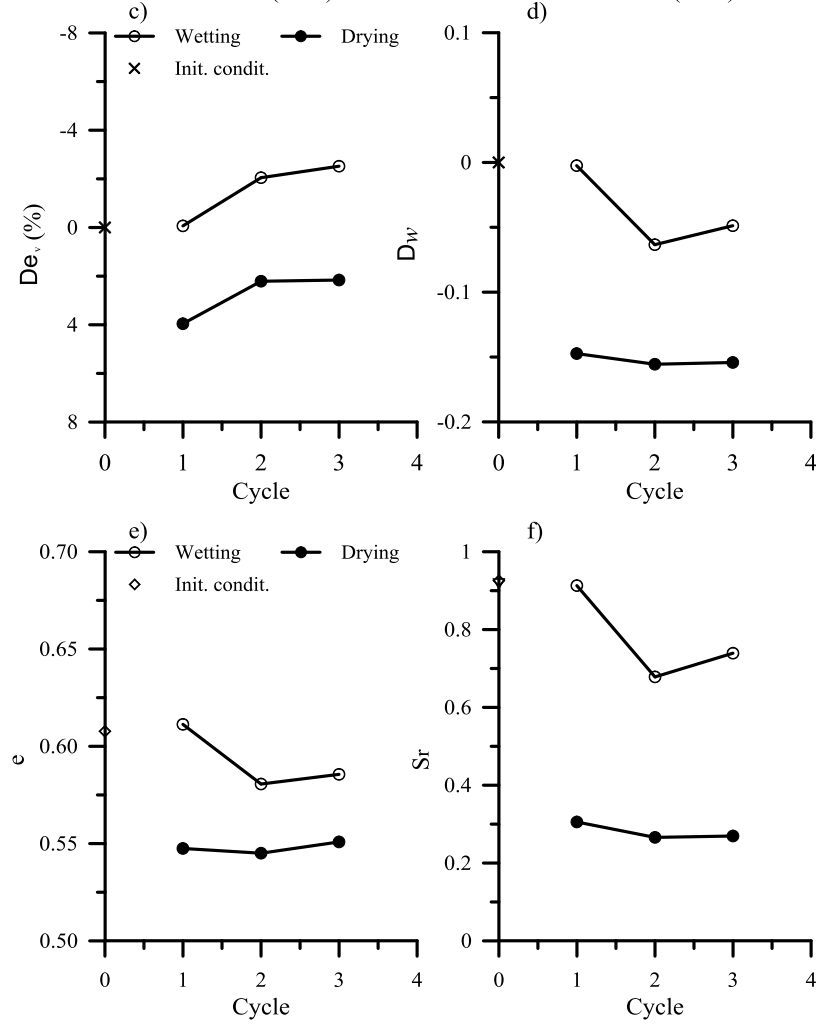

Figure 5. Evolution of Volumetric deformation, $\varepsilon_{v}$, (a), water content $w(\mathrm{~b})$, volumetric deformation changes $\Delta \varepsilon_{v}$ (c), water content variations $\Delta w(\mathrm{~d})$, void ratio $e$ (e) and degree of saturation $S_{r}$ (f) during suction cycles between 2 and $110 \mathrm{MPa}$.

In the following drying at $110 \mathrm{MPa}$ a further deformation (volumetric shrinkage) occurs that obviously deeply influences behaviour in the subsequent cycles. Drying at $110 \mathrm{MPa}$ produces volumetric shrinkage of about $5 \%$, which is not totally recovered in later wetting stages. In fact, after the second cycle, volumetric deformation changes are greatly reduced and they show opposite signs, i.e. swelling deformation in wetting and shrinkage deformation in drying. In addition, absolute values of deformation are very close and are further reduced in the third cycle.

However, it seems that volumetric deformation increases with increasing amplitude of the suction cycle and the tendency of the treated material to move towards an equilibrium characterized by reversible deformations, does not appear evident at higher suction levels.

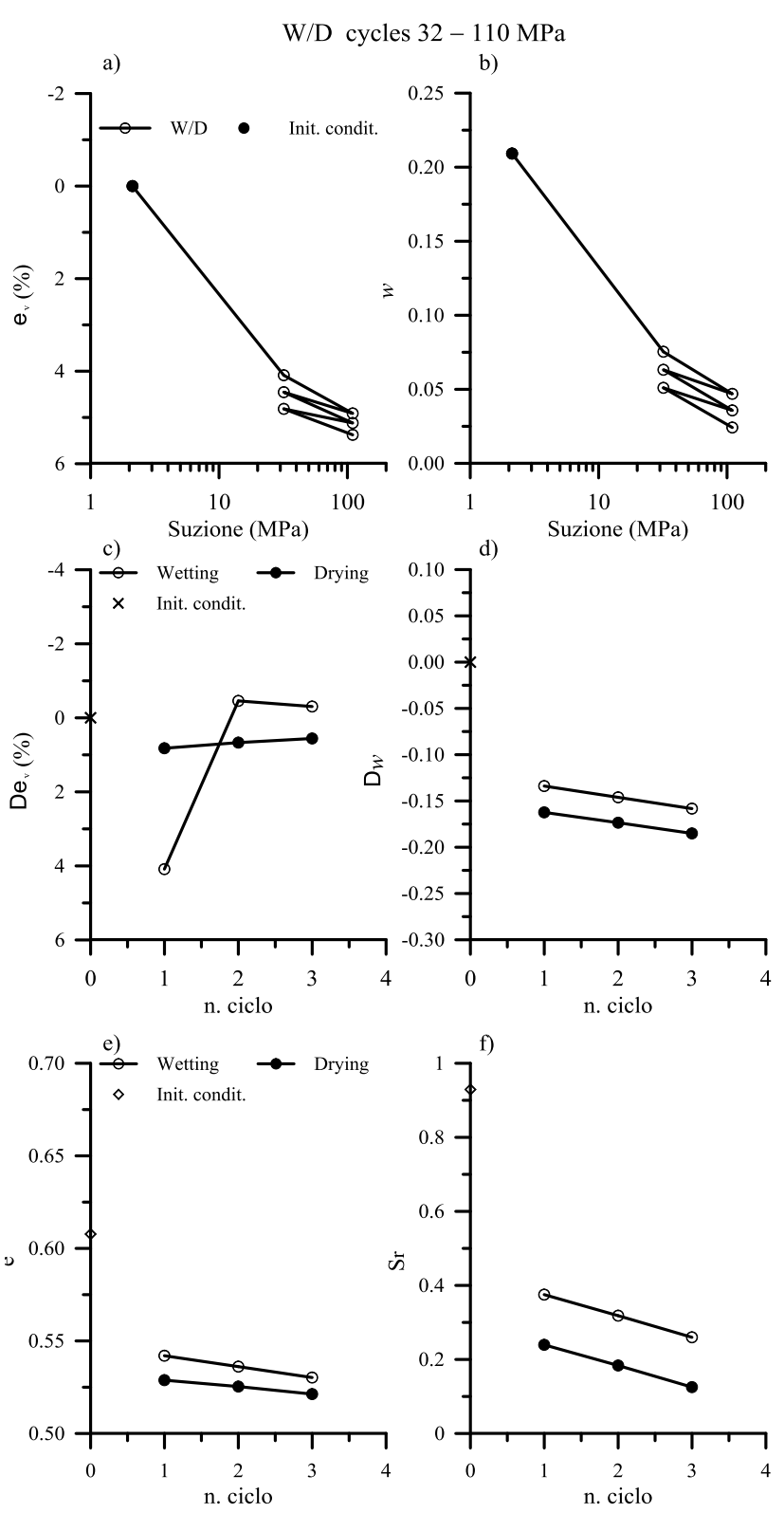

Figure 6. Evolution of Volumetric deformation, $\varepsilon_{v}$, (a), water content $w$ (b), volumetric deformation changes $\Delta \varepsilon_{v}$ (c), water content variations $\Delta w(\mathrm{~d})$, void ratio $e$ (e) and degree of saturation $S_{r}$ (f) during suction cycles between 32 and $110 \mathrm{MPa}$.

Figs. $5 c$ and $6 c$ represent the evolution of water content variation $\Delta w$ as a function of the number of cycles assuming the following convention: the volumes of water expelled from the sample (i.e. water content reductions) are considered negative and those absorbed (water content increasing) positive.

In the first equalization step a considerable loss of water content was observed for the specimen equalized to the suction of $32 \mathrm{MPa}$ (Fig. 6d). Water content variations $\Delta w$ are negligible for the specimens equalized to the suction of $4 \mathrm{MPa}$ (Fig. 5d). In the first cycle, the reduction in $w$ during the drying step is higher (in absolute value) than that of the phase of wetting, with a progressive reduction of $w$, as effect of the hydraulic hysteresis [14]. At the same time, despite the strong volumetric shrinkage, a reduction in the degree of 
saturation with the continuation of the cycles occurs (Figs. 5f and 6f).

In the subsequent cycles, the volumes of water exchanged tend to decrease, although a tendency to reversible behaviour, particularly in terms of the degree of saturation, is not less clear.

The evolution of the void ratio with the cycles of suction (Figs. 5e and 6e) reflects, of course, the evolution of the volumetric strain already examined with the diagrams in Figs. 5c and 6c. After the second cycle series, the volume variations are quite moderate.

\section{Conclusions}

The analysis of obtained results from tests performed in the suction controlled oedometer suggests that the clay treated with lime does not suffer significantly from cyclic processes of wetting and subsequent drying which develop in a range of matric suction, between 0.8 to 0.01 $\mathrm{MPa}$, lower than the initial matric suction of the specimen.

Conversely, the treated clay undergoes in a particular way, the processes of drying developing in a range of total suction higher than the initial total suction of the specimen. In fact, cyclic variations of total suction, which determine a significant drying, give rise to significant irreversible deformations of shrinkage because during the wetting stages, the material is unable to recover most of the deformations developed in the previous drying stages.

The volumetric behaviour undergoes an almost reversible pattern when the specimens are subjected to cycles between 2 and $110 \mathrm{MPa}$ while they tend to accumulate shrinkage deformation even when the total suction imposed in the wetting phase is maintained at high values (32 MPa).

The observed behavior may be interpreted with reference to the various mechanisms that control the volume response of the material to the double porosity, then considering the interactions between the microstructure and the macrostructure [15]. The triggering mechanism is due to the mutual sliding of the aggregates for the reduction of the shear resistance along the areolae of contact. This reduction can be determined by the breaking of the bonds of cementation between the aggregates of clay particles, triggered by the great loss of water, which is fundamental for the formation and permanence of cementing pozzolanic products and, only after, by the disappearance of the menisci and of their stabilizing effect.

\section{References}

1. D.I. Boardman, S. Glendinning, C.D.F. Rogers. Géotechnique 51,6:533-543 (2001)

2. P. Croce, G. Russo G., Proc. XIII European Conf. of Soil Mechanics and Geotech. Engineering (ECSMGE) (2003)

3. F.G. Bell, Eng. Geol. 42(4):223-237 (1996)

4. J. Locat, M.A. Berube, M. Choquette. Can. Geotech. J. 27(3), 294-304 (1990)

5. S. Horpibulsuk, R. Rachan, A.Chinkulkijniwat, Y. Raksachon, A. Suddeepong, Construction and Building Materials, 24, 10, 2011-2021 (2010)

6. X. Zhang, M. Mavroulidou, M.J. Gunn, Eng. Geol., 193, 320-336 (2015)

7. B. Celauro, C. Celauro, C., Construction and Building: Design, Materials, and Techniques, 1-36 (2015)

8. G. Stoltz, O. Cuisinier, F. Masrouri. Applied Clay Science, 61, 44-51 (2012)

9. C. Airò Farulla, B. Celauro, C. Celauro, M. Rosone, Ingegneria Ferroviaria 69(9), 729-752 (2014)

10. G. H. Hilt D.T. and Davidson Highway Research Board Bull., 262, 20-32 (1960)

11. J. Eades, J. R. Grim, Highway Research Record 139, 61-72 (1966)

12. E. Romero, P. Simms, P. Geotechnical and Geological Engineering 26,705-727 (2008)

13. P. Delage, M. Audigier, Y. Cui, M.D. Howat, M. D. Canad. Geotech. J. 33, 1, 150-158 (1996)

14. C. Airò Farulla, A. Battiato, A. Ferrari. In Proc. 5th Int. Conf. on Unsaturated soils, Barcelona, 417-422 (2011)

15. E.E. Alonso, J. Vaunat, A. Gens, A. Eng. Geol., 54(1-2), 173-183. (1999) 